\title{
Diagnosis of Noonan syndrome and related disorders using target next generation sequencing
}

\author{
Francesca Romana Lepri ${ }^{1 *}$, Rossana Scavelli², Maria Cristina Digilio ${ }^{1}$, Maria Gnazzo ${ }^{1}$, Simona Grotta', \\ Maria Lisa Dentici', Elisa Pisaneschi', Pietro Sirleto', Rossella Capolino', Anwar Baban', Serena Russo', \\ Tiziana Franchin ${ }^{1}$, Adriano Angioni ${ }^{1}$ and Bruno Dallapiccola ${ }^{1}$
}

\begin{abstract}
Background: Noonan syndrome is an autosomal dominant developmental disorder with a high phenotypic variability, which shares clinical features with other rare conditions, including LEOPARD syndrome, cardiofaciocutaneous syndrome, Noonan-like syndrome with loose anagen hair, and Costello syndrome. This group of related disorders, so-called RASopathies, is caused by germline mutations in distinct genes encoding for components of the RAS-MAPK signalling pathway. Due to high number of genes associated with these disorders, standard diagnostic testing requires expensive and time consuming approaches using Sanger sequencing. In this study we show how targeted Next Generation Sequencing (NGS) technique can enable accurate, faster and cost-effective diagnosis of RASopathies.

Methods: In this study we used a validation set of 10 patients ( 6 positive controls previously characterized by Sanger-sequencing and 4 negative controls) to assess the analytical sensitivity and specificity of the targeted NGS. As second step, a training set of 80 enrolled patients with a clinical suspect of RASopathies has been tested. Targeted NGS has been successfully applied over $92 \%$ of the regions of interest, including exons for the following genes: PTPN11, SOS1, RAF1, BRAF, HRAS, KRAS, NRAS, SHOC, MAP2K1, MAP2K2, CBL.

Results: All expected variants in patients belonging to the validation set have been identified by targeted NGS providing a detection rate of $100 \%$. Furthermore, all the newly detected mutations in patients from the training set have been confirmed by Sanger sequencing. Absence of any false negative event has been excluded by testing some of the negative patients, randomly selected, with Sanger sequencing.

Conclusion: Here we show how molecular testing of RASopathies by targeted NGS could allow an early and accurate diagnosis for all enrolled patients, enabling a prompt diagnosis especially for those patients with mild, non-specific or atypical features, in whom the detection of the causative mutation usually requires prolonged diagnostic timings when using standard routine. This approach strongly improved genetic counselling and clinical management.
\end{abstract}

Keywords: Noonan syndrome, Next generation sequencing, Molecular diagnosis, RASopathies

\section{Background}

Noonan syndrome (NS, OMIM 163950) is an autosomal dominant developmental disorder [1] with a prevalence ranging between 1:1.000 and 1:2.500 live births [2]. This disorder is characterized by wide phenotype variability and shares some clinical features, as facial dysmorphisms, congenital heart defect (CHD), postnatal growth

\footnotetext{
* Correspondence: francescaromana.lepri@opbg.net

${ }^{1}$ Cytogenetics, Medical Genetics and Pediatric Cardiology, Bambino Gesù Children Hospital, IRCCS, Rome, Italy

Full list of author information is available at the end of the article
}

retardation, ectodermal and skeletal defects, and variable cognitive deficits [1,2], with other rare conditions, including LEOPARD syndrome (LS, OMIM 151100) [3], cardiofaciocutaneous syndrome (CFCS, OMIM 115150) [4], Noonanlike syndrome with loose anagen hair (NS/LAH, OMIM 607721) [5], and Costello syndrome (CS, OMIM 218040) [6]. This group of related disorders is caused by germline mutations in distinct genes, encoding for components of the RAS-MAPK signalling pathway. Based on common pathogenetic mechanisms and clinical overlap, these diseases have been grouped into a single family, the so- 
called neuro-cardio-facial-cutaneous syndromes (NCFCS), recently coined RASopathies [7,8]. NS is associated with PTPN11, SOS1, KRAS, NRAS, RAF1, BRAF, SHOC2, $M E K 1$ and $C B L$ gene mutations [9-19], LS with PTPN11, $R A F 1$ and $B R A F$ gene mutations [13,17,20,21], NS/LAH with SHOC2 gene mutations [22], CFCS with KRAS, $B R A F, M E K 1$ and $M E K 2$ gene mutations [23,24], CS with HRAS gene mutations [25].

So far, the molecular characterization can be reached in approximately the $75-90 \%$ of affected individuals. Some distinct phenotypes are emerged in association with definite gene mutations.

Nowadays, due to high genetic heterogeneity of these disorders, which affect genes that all together span about $30 \mathrm{~kb}$ of genomic DNA, the standard diagnostic testing protocol requires a multi-step approach, using Sanger sequencing. The selection of the genes to investigate on a first diagnostic level depends on the frequency of their association with this disorder and their relationship with a distinct phenotype. For this reason, accurate clinical evaluation and close interaction between clinical and molecular geneticists are mandatory for selecting the genes to be first studied. By using this approach, the causative mutations can be identified in most of the cases. Some mutations cannot be identified during the first screening level since some phenotypes may be related to mutations in different causative genes or some clinical features associated with NS related disorders may not be evident at younger ages, or some extremely rare mutations are not routinely screened at first analysis. To detect these mutations, an additional screening level is required with a second panel of genes, which again should be guided by clinical geneticist. In these latter cases the molecular diagnosis requires a longer time before identifying the pathogenic mutation. Moreover, standard Sanger sequencing for multiple genes is also an expensive technique. Based on these notions, genetically heterogeneous disorders demand innovative diagnostic protocols, in order to be able to identify disease-causing mutations in a rapid and routinely way.

Here we report our personal experience on the use of targeted Next Generation Sequencing (NGS) for diagnosis of RASopathies. Our study suggests that this protocol can be easily used as a standard diagnostic tool to identify disease-causing mutations, with a straightforward workflow from genomic DNA up to genomic variants identification.

\section{Methods}

\section{Subjects}

Between June 2012 and June 2013, 80 patients (35 males and 45 females) with a clinical suspect of any RASopathy were consecutively enrolled in this study. Mean age was 8 years (range 2 months - 16 years). All patients had complete physical examination for major and minor anomalies by trained clinical geneticists (MCD, BD, RC). Two-dimensional Color-Doppler echocardiography, renal ultrasonography, and neurological/neuropsychiatric assessment for developmental delay or cognitive impairment were routinely performed. Clinical inclusion criteria were facial anomalies suggestive for RASopathies (presence of six or more features among hypertelorism, downslanting palpebral fissures, epicanthal folds, short broad nose, deeply grooved philtrum, high wide peaks of the vermilion, micrognathia, low-set and/or posteriorly angulated ears with thick helices, and low posterior hairline) [26], associated with almost one of the following clinical features: short stature, organ malformation (congenital heart defect or renal anomaly), developmental delay or cognitive deficit. All patients had normal standard chromosome analysis and array-CGH at a resolution of $75 \mathrm{~kb}$.

A total of 10 DNA samples including 6 positive controls and 4 negative controls, previously characterized by standard Sanger sequencing were used as a validation set for establishing the amplicon resequencing workflow and assessing the analytical sensitivity and specificity of the targeted NGS. A second group of 80 DNA samples, extracted from patients manifesting the RASopathies phenotype, was used as training set. The patient's genomic DNA was extracted from circulating leukocytes according to standard procedures and quantified with fluorescencebased method. Informed consent was obtained from the patients' parents. The study was approved by the institutional scientific board of Bambino Gesù Children Hospital and was conducted in accordance with the Helsinki Declaration.

\section{Targeted resequencing}

Targeted resequencing was performed using a uniquely customized design: TruSeq ${ }^{\bullet}$ Custom Amplicon (Illumina, San Diego, CA) with the MiSeq ${ }^{\bullet}$ sequencing platform (Illumina, San Diego, CA). TruSeq Custom Amplicon (TSCA) is a fully integrated DNA-to-data solution, including online probe design and ordering through the Illumina website sequencing assay automated data analysis and offline software for reviewing results.

\section{Probe design}

Online probe design was performed by entering target genomic regions into Design Studio (DS) software (Illumina, San Diego, CA). Probe design (Locus Specific Oligos) was automatically performed by DS using a proprietary algorithm that considers a range of factors, including $\mathrm{GC}$ content, specificity, probe interaction and coverage. Once the design was completed, a list of 500 bp candidate amplicons (short regions of amplified DNA) was generated and the quality of each amplicon design assessed based on the predicted success score provided by DS. 


\section{TruSeq Custom Amplicon}

\begin{tabular}{|c|c|c|}
\hline Edit Project & Manage Target & Review Design \\
\hline \multicolumn{3}{|c|}{ Review Design } \\
\hline \multicolumn{2}{|c|}{ « Back to Manage Targets } & @PRICING CALCULATOR \\
\hline
\end{tabular}

NUMBER OF TARGETS: 117

NUMBER OF ATTEMPTED AMPLICONS: 244 / 244

NUMBER OF GAPS: $\mathbf{7}$

TOTAL GAP DISTANCE: $\mathbf{1 , 0 1 0}$

CUMULATIVE TARGET (BP): $\mathbf{5 7 , 9 3 2}$

COVERAGE: $\mathbf{9 8} \%$

Figure 1 Screenshots of the designed panel within DS software.

For some targets, when required, DS has been used by the operator to edit and improve the predicted success score to a minimum value of $60 \%$. All exons with a lower success score have been removed from the design and excluded from the final TSCA panel. The design was performed over a cumulative target region of $57,932 \mathrm{bp}$ and generated a panel of 244 amplicons with a coverage of $98 \%$ of the cumulative region (Figure 1). The choice of genes investigated in this panel has been made based on scientific evidence for a causative role in the disease [9-25]. The list of the 11 genes, for a total of 132 exons, is reported in Table 1.

\section{Library preparation and sequencing}

TSCA kit generates desired targeted amplicons with the necessary sequencing adapter and indices for sequencing on the MiSeq ${ }^{\circ}$ system without any additional processing. Library preparation and sequencing runs have been performed according to manufacturer's procedure.

\section{Data analysis}

The MiSeq ${ }^{\circ}$ system provides fully integrated on-instrument data analysis software. MiSeq Reporter software performs secondary analysis on the base calls and Phredlike quality score (Qscore) generated by Real Time Analysis software (RTA) during the sequencing run. The TSCA workflow in Miseq Reporter evaluates short regions of amplified DNA (amplicons) for variants through the alignment of reads against a "manifest file" specified while starting the sequencing run. The manifest file is provided by Illumina and contains all the information on the custom assay. The TSCA workflow requires the reference genome specified in the manifest file (Homo sapiens, hg19, build 37.2). The reference genome provides variant annotations and sets the chromosome sizes in the BAM file output. The TSCA workflow performs demultiplexing of indexed reads, generates FASTQ files, aligns reads to a reference, identifies variants, and writes output files to the Alignment folder. SNPs and short indels are identified using the Genome Analysis Toolkit (GATK), by

Table 1 List of genes analyzed in this study and coverage percentage of the investigated exons

\begin{tabular}{|c|c|c|c|c|c|c|c|c|c|c|c|}
\hline Gene & PTPN11 & SOS1 & $B R A F$ & RAF1 & KRAS & NRAS & HRAS & SHOC2 & MAP2K1 & MAP2K2 & $C B L$ \\
\hline Number of exons uploaded into DS & 15 & 23 & 18 & 16 & 5 & 4 & 5 & 8 & 11 & 11 & 16 \\
\hline $\begin{array}{l}\text { Number of exons entirely covered by DS } \\
\text { with predicted success score }>60 \%\end{array}$ & 14 & 23 & 18 & 16 & 5 & 3 & 5 & 8 & 11 & 11 & 16 \\
\hline $\begin{array}{c}\text { Total exons covered by DS/ total exons } \\
\text { uploaded into DS (\%) }\end{array}$ & & & & & & 98.5 & & & & & \\
\hline $\begin{array}{l}\text { Number of exons successfully sequenced } \\
\text { with coverage }>30\end{array}$ & 13 & 22 & 16 & 16 & 5 & 3 & 5 & 8 & 9 & 9 & 14 \\
\hline $\begin{array}{c}\text { Total exons successfully sequenced/ total } \\
\text { exons covered by DS (\%) }\end{array}$ & & & & & & $92.4 \%$ & & & & & \\
\hline
\end{tabular}




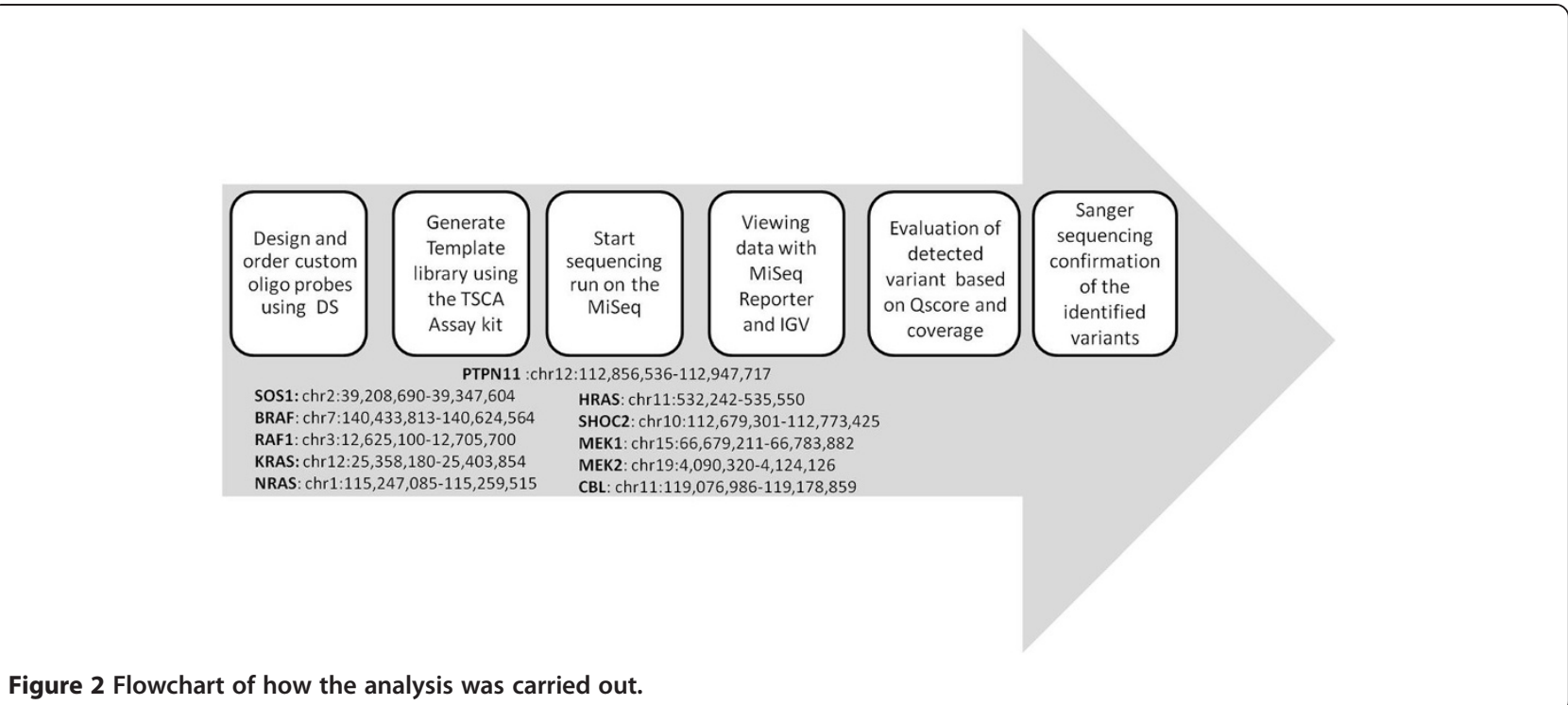

default. GATK calls raw variants for each sample, analyzes variants against known variants, and then calculates a false discovery rate for each variant. Variants are flagged as homozygous (1/1) or heterozygous (0/1) in the Variant Call File sample column. Because a SNP database (dbSNP (http://www.ncbi.nlm.nih.gov/projects/SNP) is available in the Annotation subfolder of the reference genome folder, any known SNPs or indels are flagged in the VCF output file. A reference gene database is available in the Annotation subfolder of the reference genome folder and any SNPs or indels that occur within known genes are annotated.

Each single variant reported in the VCF output file has been evaluated for the coverage and the Qscore and visualized via Integrative Genome Viewer (IGV) $[27,28]$. Based on the guidelines of the American College of Medical Genetics and Genomics [29], all regions that have been sequenced with a sequencing depth $<30$ have been considered not suitable for analysis. Furthermore we established a minimum threshold in Qscore of 30 (base call accuracy of 99.9\%).

\section{Sanger sequencing validation}

All mutations identified by Miseq Reporter have been validated by Sanger sequencing using standard protocols and, where possible, family members were tested to detect the "de novo" origin of the mutation. Figure 2 shows the flowchart of the above described method.

\section{Results}

\section{TSCA performance}

All coding regions for genes reported in Table 1 have been uploaded into DS for a total of 132 exons (cumulative target region of $57,932 \mathrm{bp}$ ). The $98.5 \%$ of the exons uploaded were covered by the amplicon design, with a predicted success score $\geq 60 \%$. The remaining exons not entirely covered by DS or with a predicted success score $<60 \%$ have been excluded from final TSCA content panel. TSCA sequencing runs generated 120 exons successfully and steadily sequenced (sequencing depth $>30$, Qscore $>30$ ), providing a total coverage of $91 \%$ of the overall of the exons uploaded into DS, and a coverage of $92 \%$ when referring to the number of exons covered by DS (Table 1). The TSCA approach reduced up to 12 the number of exons requiring the standard Sanger sequencing analysis.

\section{Validation set}

TSCA sequencing of 4 negative control confirmed the absence of any variant and the analysis of 6 positive

Table 2 List of patients with known mutations included in the validation set

\begin{tabular}{ccccccc}
\hline Patient ID & Gene & Mutation & Allele state & Mutation detected by TSCA sequencing & Coverage & Qscore \\
\hline $\mathbf{1}$ & PTPN11 & Y63C & het & Y63C & 374 \\
$\mathbf{2}$ & PTPN11 & N308D & het & N308D & 519 & 39 \\
$\mathbf{3}$ & PTPN11 & T468M & het & T468M & 525 & 40 \\
$\mathbf{4}$ & SOS1 & M279R & het & M279R & 390 & 39 \\
$\mathbf{5}$ & SOS1 & I733N & het & G173N & 37 \\
$\mathbf{6}$ & HRAS & G12A & het & G12A & 37 \\
\hline
\end{tabular}


control samples confirmed both the expected mutations and the allele state. All variants were identified with a mean coverage of 318 and a mean Qscore $=38$, providing a detection rate of $100 \%$ for the validation set (Table 2). Both positive and negative control samples did not highlight any further unexpected variant, confirming the absence of any unreported variant in the validation set, and of any false positive result.

\section{Training set}

Samples from training set were investigated in three different sequencing runs, with an average coverage of

Table 3 Mutations identified by TSCA sequencing in patients enrolled in the training set

\begin{tabular}{|c|c|c|c|c|c|c|c|c|c|}
\hline Case & Phenotype & Gene & Mutation & Protein substitution & Allele state & Variant frequency & Coverage & Qscore & Reference \\
\hline 1 & NS & PTPN11 & c. $184 \mathrm{~T}>\mathrm{G}$ & Y62D & het & 0.448 & 460 & 39 & [30] \\
\hline 2 & NS & PTPN11 & c. $188 \mathrm{~A}>\mathrm{G}$ & Y63C & het & 0.521 & 190 & 39 & [9] \\
\hline 3 & NS & PTPN11 & c. $188 \mathrm{~A}>\mathrm{G}$ & Y63C & het & 0.54 & 512 & 39 & [9] \\
\hline 4 & NS & PTPN11 & c. $188 \mathrm{~A}>\mathrm{G}$ & Y63C & het & 0.481 & 1046 & 38 & [9] \\
\hline 5 & NS & PTPN11 & c. $317 A>C$ & D106A & het & 0.495 & 632 & 39 & [31] \\
\hline 6 & NS & PTPN11 & c. $328 \mathrm{G}>\mathrm{A}$ & E110K & het & 0.486 & 702 & 36 & [31] \\
\hline 7 & NS & PTPN11 & $c .417 \mathrm{G}>\mathrm{C}$ & E139D & het & 0.498 & 406 & 38 & [30] \\
\hline 8 & NS & PTPN11 & c. $661 \mathrm{~A}>\mathrm{G}$ & $1221 \mathrm{~V}$ & het & 0.482 & 737 & 39 & p.s \\
\hline 9 & NS & PTPN11 & c. $767 A>G$ & Q256R & het & 0.514 & 290 & 36 & p.s \\
\hline 10 & NS & PTPN11 & c.854 T>C & F285S & het & 0.406 & 64 & 39 & [30] \\
\hline 11 & NS & PTPN11 & c. $922 \mathrm{~A}>\mathrm{G}$ & N308D & het & 0.526 & 812 & 38 & [9] \\
\hline 12 & NS & PTPN11 & c. $922 \mathrm{~A}>\mathrm{G}$ & N308D & het & 0.508 & 1174 & 39 & [9] \\
\hline 13 & NS & PTPN11 & c. $922 \mathrm{~A}>\mathrm{G}$ & N308D & het & 0.505 & 3126 & 39 & [9] \\
\hline 14 & NS & PTPN11 & c. $922 \mathrm{~A}>\mathrm{G}$ & N308D & het & 0.486 & 3111 & 39 & [9] \\
\hline 15 & NS & PTPN11 & c. $923 \mathrm{~A}>\mathrm{G}$ & N308S & het & 0.555 & 119 & 40 & [30] \\
\hline 16 & NS & PTPN11 & c. $1183 \mathrm{G}>\mathrm{T}$ & D395Y & het & 0.556 & 561 & 38 & p.s \\
\hline 16 & NS & PTPN11 & C.1186 T>C & Y396H & het & 0.557 & 560 & 37 & p.s \\
\hline 17 & NS & PTPN11 & c. $1226 \mathrm{G}>\mathrm{C}$ & G409A & het & 0.444 & 178 & 38 & [32] \\
\hline 18 & NS & PTPN11 & c. $1282 \mathrm{G}>\mathrm{T}$ & V428L & het & 0.502 & 416 & 38 & p.s \\
\hline 19 & LS & PTPN11 & c. $1403 C>T$ & $\mathrm{~T} 468 \mathrm{M}$ & het & 0.467 & 319 & 40 & [20] \\
\hline 20 & LS & PTPN11 & c.1492 C> T & R498W & het & 0.573 & 185 & 35 & [33] \\
\hline 21 & LS & PTPN11 & c.1492 C> T & R498W & het & 0.521 & 142 & 38 & [33] \\
\hline 22 & NS & SOS1 & c.755 T>C & $1252 \mathrm{~T}$ & het & 0.528 & 212 & 39 & [34] \\
\hline 23 & NS & SOS1 & c.806 T > G & M269R & het & 0.564 & 140 & 38 & [34] \\
\hline 24 & NS & SOS1 & $\mathrm{c} .806 \mathrm{~T}>\mathrm{G}$ & M269R & het & 0.496 & 391 & 38 & [34] \\
\hline 25 & NS & SOS1 & c. $1310 \mathrm{~T}>\mathrm{A}$ & $1437 \mathrm{~N}$ & het & 0.46 & 302 & 40 & [34] \\
\hline 26 & NS & SOS1 & c.1649 T>C & L550P & het & 0.516 & 275 & 39 & [34] \\
\hline 27 & NS & SOS1 & C.1649 T>C & L550P & het & 0.428 & 428 & 39 & [34] \\
\hline 28 & NS & SOS1 & c. $2104 \mathrm{~T}>\mathrm{C}$ & $\mathrm{Y} 702 \mathrm{H}$ & het & 0.52 & 421 & 37 & [34] \\
\hline 29 & NS & SOS1 & c. $2371 C>A$ & L791I & het & 0.576 & 363 & 37 & p.s \\
\hline 30 & NS & SOS1 & $c .2371 C>A$ & L791। & het & 0.546 & 108 & 39 & p.s \\
\hline 31 & NS/CFCS & $B R A F$ & c. $1694 \mathrm{~A}>\mathrm{G}$ & D565G & het & 0.463 & 341 & 39 & p.s \\
\hline 32 & CFCS & $B R A F$ & c. $1802 \mathrm{~A}>\mathrm{T}$ & K601I & het & 0.538 & 1120 & 37 & {$[17]$} \\
\hline 33 & CFC & MEK2 & c. $326 C>T$ & $\mathrm{~A} 110 \mathrm{~T}$ & het & 0.505 & 299 & 37 & p.s \\
\hline 34 & CFC & MEK2 & c. 395 T> G & G132D & het & 0.533 & 227 & 38 & [35] \\
\hline 35 & NS & RAF1 & c.785 A > T & N262I & het & 0.504 & 135 & 39 & p.s \\
\hline 36 & NS & RAFI & c. $781 C>T$ & P261S & het & 0.524 & 143 & 39 & [13] \\
\hline 37 & NS & $C B L$ & $c .2350 G>A$ & V784M & het & 0.428 & 173 & 36 & p.s \\
\hline
\end{tabular}

p.s: present study. 

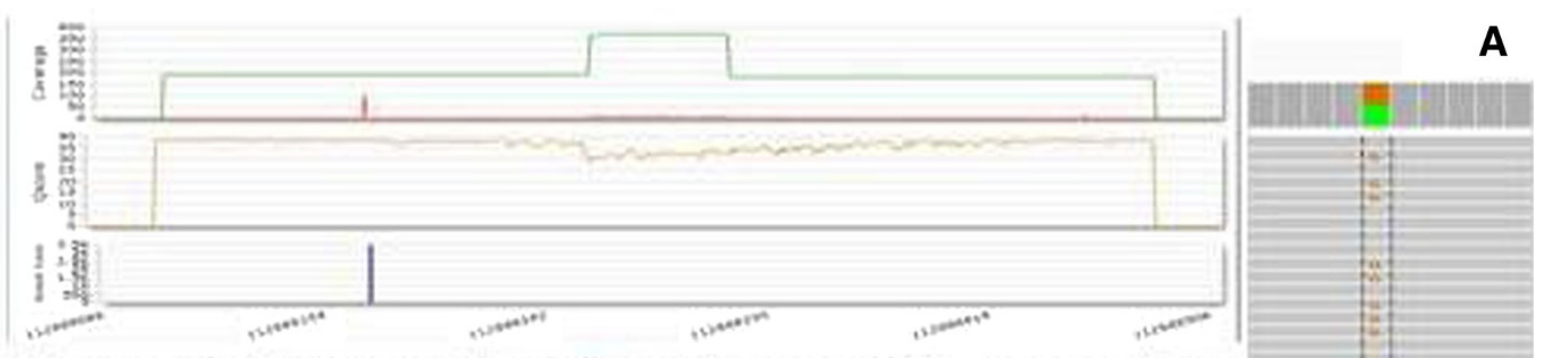

AACACTGGTGATTACTPTGACCTGTATGGAGGG AACACTGGTGATTACTRTGACCTGTATGGAGGG

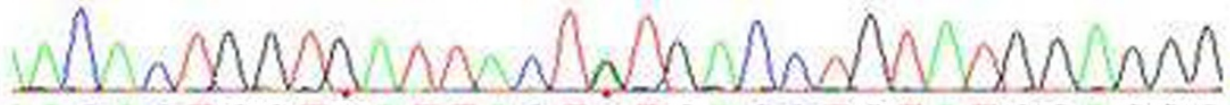
AAACTGGT\&ATTACTrTGACCTGTATGGAGGG

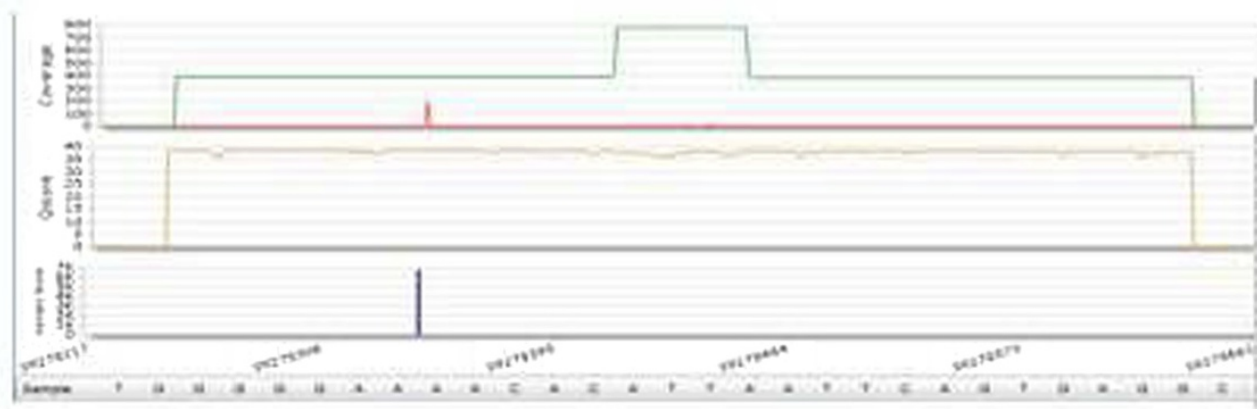

ITAGAAGATACAGTAGAAAKGACAGATGAAGGCAGTCCCC

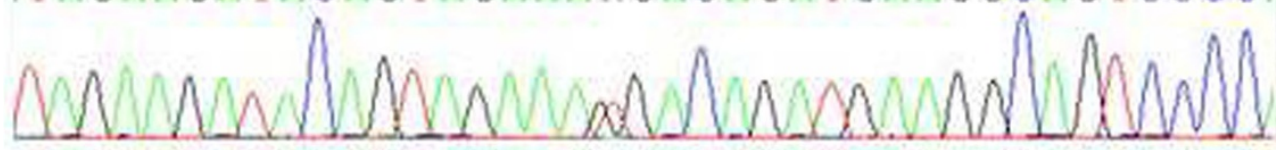
TAGAAGATACAGTAGAAAKGACAGATGAAGGCAGTCCCC

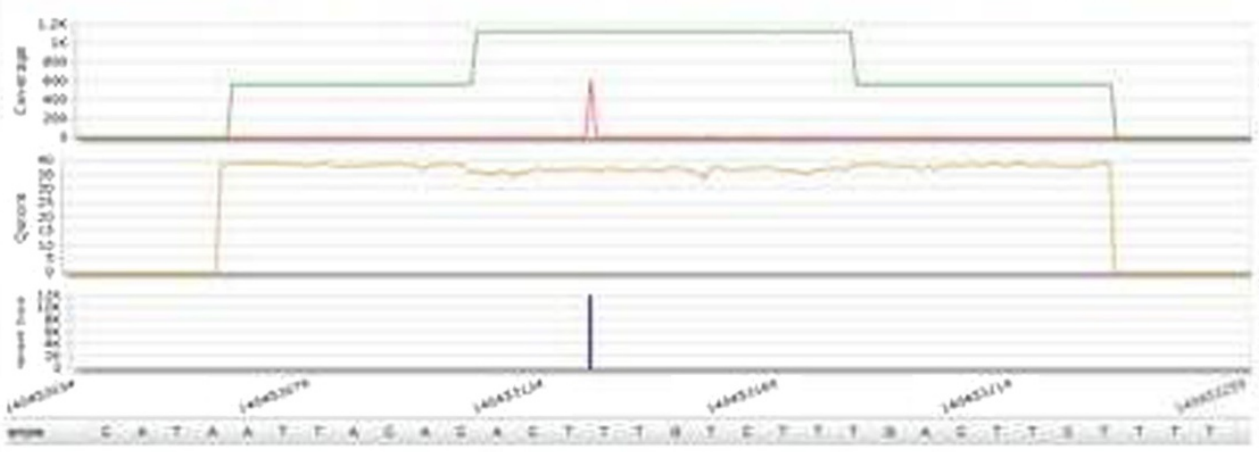

GGTGATTTTGGTCTAGCTACAGTGAWATCTCGATGGAGTGGGT

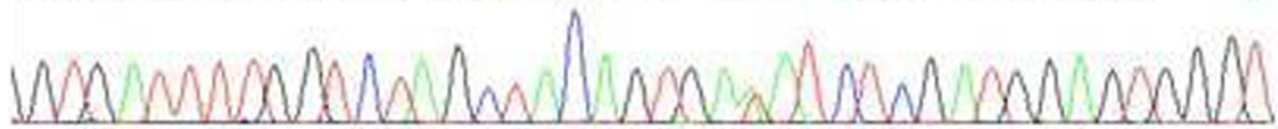
GGTGATTTTGGTCTAGCTACAGTGAWATCTCGATGGAGTGGGT

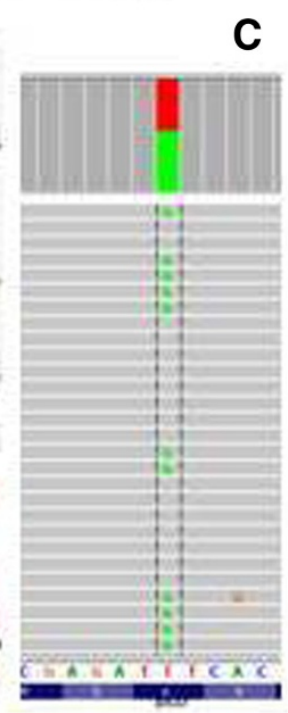

Figure 3 An example of three different mutations (A. PTPN11:Y63C; B. SOS1: M269R; C. BRAF: K6011) identified by Miseq. 
200x, as set with DS. Among the patients, 38 mutations were identified in 6 of the 11 RAS pathway genes analyzed, PTPN11 (22/38 = 58\%), SOS1 $(9 / 38=23 \%), B R A F$ $(2 / 38=5 \%), M E K 2(2 / 38=5 \%), R A F 1 \quad(2 / 38=5 \%), C B L$ $(1 / 38=3 \%)$. The 38 variants identified from Miseq Reporter had an average coverage of $595 \mathrm{x}$ and an average Qscore of 38 (Table 3).

All variants have been confirmed by Sanger sequencing and IGV, indicating the absence of any false positive result in the training set group (Figure 3). Moreover, to exclude any possible false negative event, 10 negative samples randomly selected, have been further analyzed by Sanger sequencing (only "hot spots" exons) and 30 additional samples have been analyzed for PTPN11, using NGS and Sanger sequencing and all of them provided negative results.

\section{Reproducibility}

TSCA sequencing showed 100\% reproducibility for all 120 exons, independently from DNA samples and sequencing runs, making this approach compatible with a diagnostic purpose. Figure 4 illustrates the performance of the same target region through three sequencing runs.

\section{Discussion}

The term RASopathy applies to a group of genetic disorders characterized by similar phenotypes, caused by mutations in the RAS MAPK pathway. These phenotypes are characterized by a high degree of genetic heterogeneity, since individual diseases can arise from mutations in different genes. In addition, since different RASopathies share similar clinical features, their molecular characterization is complex, time consuming and expensive.

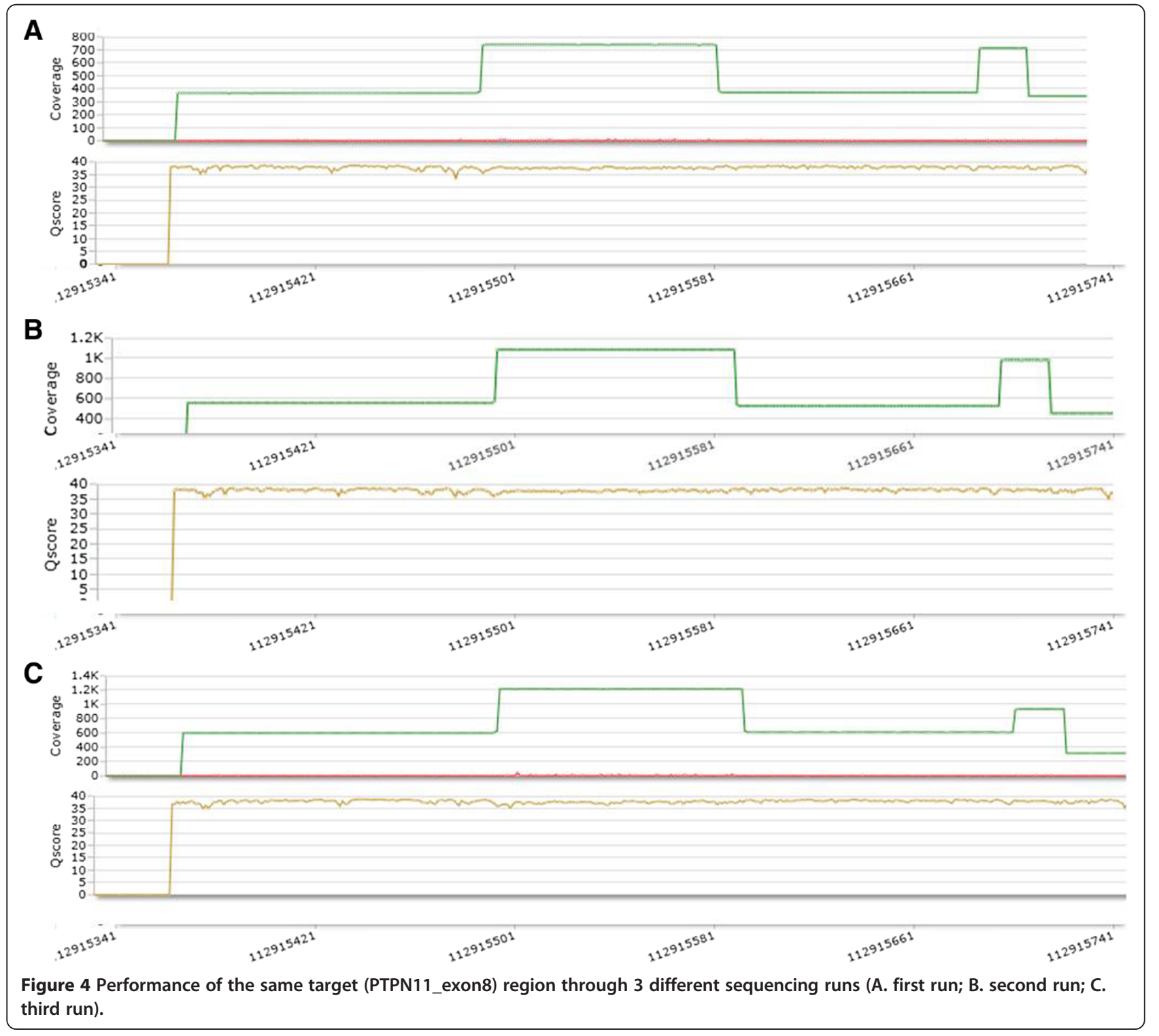


Table 4 Clinical features of the patients carrying rare PTPN11 mutations

\begin{tabular}{|c|c|c|c|c|c|c|c|}
\hline & Case $n^{\circ} 8$ & Case $n^{\circ} 9$ & Case $n^{\circ} 10$ & Case $n^{\circ} 16$ & Father case $n^{\circ} 16$ & Case $n^{\circ} 18$ & Mother case $n^{\circ} 18$ \\
\hline \multicolumn{8}{|l|}{ Sex } \\
\hline \multicolumn{8}{|l|}{ Short stature } \\
\hline Macrocephaly & + & - & + & - & - & & \\
\hline \multicolumn{8}{|l|}{ Hypertelorism } \\
\hline \multicolumn{8}{|l|}{ Downslanting palpebral fissures } \\
\hline Palpebral ptosis & - & - & + & - & + & + & + \\
\hline Epicanthal folds & + & + & - & + & - & & \\
\hline Short broad nose & + & + & - & + & - & - & \\
\hline Deeply grooved philtrum & + & + & + & + & + & & \\
\hline High wide peaks of the vermilion & + & + & + & + & + & + & + \\
\hline Micrognathia & - & + & - & & & & \\
\hline \multicolumn{8}{|l|}{$\begin{array}{l}\text { Low-set and/or posteriorly angulated } \\
\text { ears with thick helices }\end{array}$} \\
\hline Low posterior hairline & - & + & + & - & - & + & - \\
\hline Thorax anomalies & - & + & + & - & - & + & - \\
\hline Cardiac defect & + & + & - & - & - & & \\
\hline - PVS & - & + & + & - & - & - & - \\
\hline - ASD & - & - & - & & & & \\
\hline - VSD & - & - & - & - & - & & \\
\hline - PDA & - & + & - & - & - & & \\
\hline Arrhythmia & - & - & - & - & - & WPW & - \\
\hline Renal anomaly & - & - & - & - & - & - & - \\
\hline Cryptorchidism & NA & - & - & + & NA & & \\
\hline \multicolumn{8}{|c|}{ Developmental delay or cognitive deficit } \\
\hline Alopecia & - & - & + & + & - & & \\
\hline Pancreatic cyst & + & - & - & - & - & & \\
\hline Angioma & - & - & - & - & - & & \\
\hline Inheritance & NT & pat & NT & mat & NT & & \\
\hline
\end{tabular}

ASD, atrial septal defect; VSD, ventricular septal defect; HCM, hypertrophic cardiomyopathy; mat, maternal; NA, not applicable; NT, not tested; pat, paternal; PDA, patent ductus arteriosus; PVS, pulmonary valve stenosis; WPW, Wolf-Parkinson-White.

+present; -not present.

In order to improve the molecular testing of RASopathies, in this study we investigated a protocol based on a targeted NGS using MiSeq Illumina platform enabling the analysis of all known causative genes in up to 96 patients in a single sequencing run. In particular, we analyzed 80 patients and identified 38 mutations in 6 of 11 RASpathway genes, including PTPN11 $(22 / 38=58 \%)$, SOS1 $(9 / 38=23 \%), \quad B R A F \quad(2 / 38=5 \%), \quad M E K 2 \quad(2 / 38=5 \%)$, RAF1 $(2 / 38=5 \%), C B L(1 / 38=3 \%)$. The relative frequency of mutations in the tested genes was in agreement with published results $[30,36,37]$. As shown in Table 3 , in many patients the causal mutation was identified in the gene considered the most suitable candidate, based on frequency of mutations and the phenotypic characteristics. As expected, most NS patients had a PTPN11 mutation, while the second most frequently mutated gene was SOS1, followed by RAF1. Three patients with LEOPARD syndrome had one of the PTPN11 recurrent mutation previously associated with this phenotype (T468M or R498W) [20,33]. Among patients heterozygous for a pathogenic BRAF mutation, one was clinically diagnosed as being affected by CFCS, while in the other case clinical evaluation was unable to conclude whether he was affected by NS or CFCS. The patients' age at diagnosis is obviously important: this latter subject was 2 year-old at time of clinical evaluation, when he displayed only some features of CFCS [38]. Two other patients with CFCS had a mutation in $M E K 2$ gene, which is less commonly mutated in this disorder. In addition, one NS patient had a mutation in $C B L$, a gene rarely associated with this disorder. Since all genes have been analyzed in one run, the present protocol allowed to reach the 

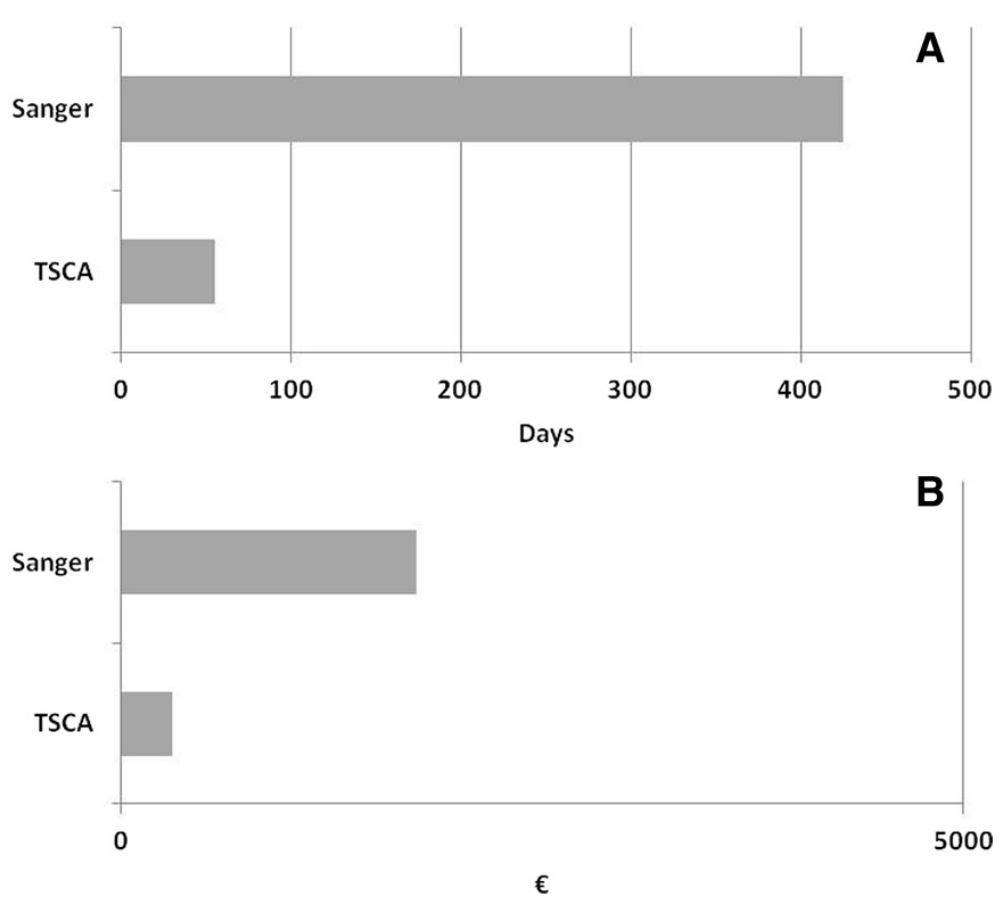

Figure 5 Comparison of time (A) and cost (B) between NGS and Sanger sequencing.

simultaneous identification of mutations affecting both the most frequent and rare genes, with a significantly reduction of time needed to reach the molecular characterization of the patient. This point is important for early diagnosis and classification of the different RASopathies, allowing a more appropriate management and counseling.

A wide spectrum of PTPN11 mutations has been associated with NS, including some rare mutations: I221V, Q256R, F285S, V428L (Table 4). All these variants are associated with the distinct facial gestalt of NS, which was markedly expressed in one patient (case no.10) with F285S and mildly expressed in the others. Familial transmission from an affected individual has been found in one instance, and suspected in another case (no.8), where the affected proband's brother was referred to have membranous subaortic stenosis and cryptorchidism. Mental retardation or cognitive deficit was not associated with these mutations, with the exception of F285S mutation. Interestingly, the patient heterozygous for this latter mutation had a congenital pancreatic cyst, an unusual malformation in the RASopathies. In one patient (case no.16) we identified two unpublished mutations affecting two consecutive PTPN11 aminoacids, D395Y and Y396H. Both mutations were inherited from the affected father. Variability of clinical expression in this family was recognizable, since facial anomalies of NS were associated with developmental delay in the son only. The father had congenital total alopecia as distinctive feature. It is evident that the phenotype related to these mutations is quite atypical, showing common Noonan-like facial anomalies associated with variable additional neural and ectodermal features.

The other 43 patients enrolled in this study were negative for the investigated RAS genes. The proportion of negative patients was higher compared to previous reports, likely because clinical inclusion criteria were less stringent compared to other studies [39-41], being based on NS facial anomalies and almost only one additional feature. Interestingly, the mother of patient $\mathrm{n}^{\circ} 18$ was included in this study being the mutated parent of an affected child, although the minimal clinical criteria for diagnosis of NS were not present.

All the variations have been confirmed by Sanger sequencing as well as the 4 negative control patients. These data indicated a $100 \%$ detection rate of mutations involved in RASopathies and, most important, all these results have been obtained with MiSeq on board analysis, being the bioinformatics examination performed only adopting the user friendly Miseq Reporter software.

The absence of any false negative and false positive results and the possibility to have an easy and accurate data analysis make this approach a good diagnostic tool. Furthermore, the library preparation workflow is easy and the TSCA kit performance is stable. In fact, all different experiments for the RAS pathway genes in each run provided the same results in terms of coverage and quality (Figure 4). 
Two major points to be considered in the diagnostic protocols include the time needed to complete the entire workflow and the costs that this approach requires. Targeted NGS analysis of the complete coding sequences of the 11 genes in the RAS pathway for 96 patients takes about two months, including ten days for library preparation and data analysis and about 45 days to characterize uncovered regions using Sanger sequencing. Conversely, the use of Sanger sequencing to analyze the full coding sequence of the 11 genes would take about 16-18 months for the same number of patients. We also calculated that the cost of NGS analysis applied to the $92 \%$ of the regions of interest, plus Sanger sequencing of for the remaining regions, would cost 6 time less than the cost of a protocol entirely based on Sanger sequencing (Figure 5). However, time and cost could be further reduced, by designing a new panel which includes also RIT1, a gene recently associated to NS [42], resulting in a 100\% coverage of the cumulative region. This result likely makes the Sanger sequencing irrelevant for the analysis, further reducing the time and the cost of the entire process.

\section{Conclusion}

This study demonstrates that NGS can be successfully applied to the molecular testing of RASophaties with a remarkable gain of time and less cost, while maintaining the high quality of the results. Consistent with available records, our data confirm that the genetic mechanism underlying the RASopathies is due to germline mutations in different genes encoding for components of the RASMAPK signalling mutations, with PTPN11, followed by SOS1, being the most frequently mutated genes in our cohort. Moreover, the use of NGS protocol has allowed, with a high standard in terms of coverage and quality, an early detection of rare mutations in other RAS-MAPK genes, avoiding the use of standard Sanger sequencing approach and the related enlarged cost and time consuming issues. Taken all together, these data highlight the usefulness of a molecular characterization that lead to an early diagnosis especially for patients with mild, nonspecific or atypical features and might direct to a more appropriate genetic counselling and clinical management.

\footnotetext{
Abbreviations

NS: Noonan syndrome; LS: LEOPARD syndrome; CFCS: Cardiofaciocutaneous syndrome; NS/LAH: Noonan-like syndrome with loose anagen hair; CS: Costello syndrome; NGS: Next generation sequencing; M.C.D: Maria Cristina Digilio; B.D: Bruno Dallapiccola; R.C: Rossella Capolino; TSCA: TruSeq custom amplicon; DS: Design studio software; GATK: Genome analysis Toolkit; RTA: Real time analysis software; IGV: Integrative genome viewer; p.s.: Present study,
}

\section{Competing interests}

The authors declare that they have no competing interests.

\section{Authors' contributions}

FRL: carried out the molecular genetic studies, the analysis and interpretation of data and drafted the manuscript. RS: participated to analysis and interpretation of data and drafted the manuscript. MCD, BD and MLD performed the clinical examination of the patients and have been involved in drafting the manuscript. MG, SG, EP, PS and SR: contribute to perform the molecular genetic studies and analysis and interpretation of data. RC and $A B$ : performed the clinical examination. TF: contribute to perform the analysis and interpretation of data. AA: contribute to concept the study and has been involved in drafting the manuscript. All authors read and approved the final manuscript.

\section{Acknowledgements}

This study was supported by grants from the Italian Ministry of Health, Ricerca Corrente 2013.

\section{Author details}

${ }^{1}$ Cytogenetics, Medical Genetics and Pediatric Cardiology, Bambino Gesù Children Hospital, IRCCS, Rome, Italy. ${ }^{2}$ lllumina, Inc., San Diego, CA 92122, USA.

Received: 25 September 2013 Accepted: 20 January 2014

Published: 23 January 2014

\section{References}

1. Noonan JA: Hypertelorism with Turner phenotype. A new syndrome with associated congenital heart disease. Am J Dis Child 1968, 116:373e380.

2. Nora JJ, Nora AH, Sinha AK, Spangler RD, Lubs HA: The Ullriche-Noonan syndrome (Turner phenotype). Am J Dis Child 1974, 127:48e55.

3. Gorlin RJ, Anderson RC, Blaw M: Multiples lentigienes syndrome syndrome. Am J Dis Child 1969, 117:652-662.

4. Reynolds JF, Neri G, Herrmann JP, Blumberg B, Coldwell JG, Miles PV, Opitz JM: New multiple congenital anomalies/mental retardation syndrome with cardio-facio-cutaneous involvement-the CFC syndrome. Am J Med Genet 1986, 25(3):413-427.

5. Mazzanti L, Cacciari E, Cicognani A, Bergamaschi R, Scarano E, Forabosco A Noonan-like syndrome with loose anagen hair: a new syndrome? Am J Med Genet A 2003, 118A(3):279-286.

6. Costello JM: A new syndrome: mental subnormality and nasal papillomata. Aust Paediatr J 1977, 13(2):114-118.

7. Bentires-Alj M, Kontaridis MI, Neel BG: Stops along the RAS pathway in human genetic disease. Nat Med 2006, 12:283-285.

8. Tidyman WE, Rauen KA: The RASopathies: developmental syndromes of Ras/MAPK pathway dysregulation. Curr Opin Genet Dev 2009, 19:230-236.

9. Tartaglia M, Mehler EL, Goldberg R, Zampino G, Brunner HG, Kremer H, van der Burgt I, Crosby AH, Ion A, Jeffery S, Kalidas K, Patton MA, Kucherlapati RS, Gelb BD: Mutations in PTPN11,encoding the protein tyrosine phosphatase SHP-2, cause Noonan syndrome. Nat Genet 2001, 29:465-468.

10. Tartaglia M, Pennacchio LA, Zhao C, Yadav KK, Fodale V, Sarkozy A, Pandit B, Oishi K, Martinelli S, Schackwitz W, Ustaszewska A, Martin J, Bristow J, Carta C, Lepri F, Neri C, Vasta I, Gibson K, Curry CJ, Siguero JP, Digilio MC, Zampino G, Dallapiccola B, Bar-Sagi D, Gelb BD: Gain-of-function SOS1 mutations cause a distinctive form of Noonan syndrome. Nat Genet 2007, 39(1):75-79.

11. Carta C, Pantaleoni F, Bocchinfuso G, Stella L, Vasta I, Sarkozy A, Digilio C, Palleschi A, Pizzuti A, Grammatico P, Zampino G, Dallapiccola B, Gelb BD, Tartaglia M: Germline missense mutations affecting KRAS isoform $B$ are associated with a severe Noonan syndrome phenotype. Am J Hum Genet 2006, 79:129-135.

12. Schubbert S, Zenker M, Rowe SL, Böll S, Klein C, Bollag G, van der Burgt I, Musante L, Kalscheuer V, Wehner LE, Nguyen H, West B, Zhang KY, Sistermans E, Rauch A, Niemeyer CM, Shannon K, Kratz CP: Germline KRAS mutations cause Noonan syndrome. Nat Genet 2006, 38:331-336.

13. Pandit B, Sarkozy A, Pennacchio LA, Carta C, Oishi K, Martinelli S, Pogna EA, Schackwitz W, Ustaszewska A, Landstrom A, Bos JM, Ommen SR, Esposito G, Lepri F, Faul C, Mundel P, López Siguero JP, Tenconi R, Selicorni A, Rossi C, Mazzanti L, Torrente I, Marino B, Digilio MC, Zampino G, Ackerman MJ, Dallapiccola B, Tartaglia M, Gelb BD: Gain-of-function RAF1 mutations cause Noonan and LEOPARD syndromes with hypertrophic cardiomyopathy. Nat Genet 2007, 39:1007-1012.

14. Razzaque MA, Nishizawa T, Komoike Y, Yagi H, Furutani M, Amo R, Kamisago M, Momma K, Katayama H, Nakagawa M, Fujiwara Y, Matsushima M, Mizuno K, Tokuyama M, Hirota H, Muneuchi J, Higashinakagawa T, Matsuoka R: Germline gain-of-function mutations in RAF1 cause Noonan syndrome. Nat Genet 2007, 39:1013-1017.

15. Roberts AE, Araki T, Swanson KD, Montgomery KT, Schiripo TA, Joshi VA, Li L, Yassin Y, Tamburino AM, Neel BG, Kucherlapati RS: Germline gain- 
offunction mutations in SOS1 cause Noonan syndrome. Nat Genet 2007, 39:70-74.

16. Nava $C$, Hanna N, Michot $C$, Pereira S, Pouvreau N, Niihori T, Aoki Y, Matsubara Y, Arveiler B, Lacombe D, Pasmant E, Parfait B, Baumann C, Héron D, Sigaudy S, Toutain A, Rio M, Goldenberg A, Leheup B, Verloes A, Cavé H: Cardio-facio-cutaneous and Noonan syndromes due to mutations in the RAS/MAPK signaling pathway: genoype-phenotype relationships and overlap with Costello syndrome. J Med Genet 2007, 44(12):763-771.

17. Sarkozy A, Carta C, Moretti S, Zampino G, Digilio MC, Pantaleoni F, Scioletti AP, Esposito G, Cordeddu V, Lepri F, Petrangeli V, Dentici ML, Mancini GM, Selicorni A, Rossi C, Mazzanti L, Marino B, Ferrero GB, Silengo MC, Memo L, Stanzial F, Faravelli F, Stuppia L, Puxeddu E, Gelb BD, Dallapiccola B, Tartaglia M: Germline BRAF mutations in Noonan, LEOPARD, and cardiofaciocutaneous syndromes: molecular diversity and associated phenotypic spectrum. Hum Mut 2009, 30:695-702

18. Cirstea IC, Kutsche K, Dvorsky R, Gremer L, Carta C, Horn D, Roberts AE, Lepri F, Merbitz-Zahradnik T, König R, Kratz CP, Pantaleoni F, Dentici ML, Joshi VA, Kucherlapati RS, Mazzanti L, Mundlos S, Patton MA, Silengo MC, Rossi C, Zampino G, Digilio C, Stuppia L, Seemanova E, Pennacchio LA, Gelb BD, Dallapiccola B, Wittinghofer A, Ahmadian MR, Tartaglia M, Zenker M: A restricted spectrum of NRAS mutations causes Noonan syndrome. Nat Genet Jan 2010, 42:27-29.

19. Martinelli S, De Luca A, Stellacci E, Rossi C, Checquolo S, Lepri F, Caputo V Silvano M, Buscherini F, Consoli F, Ferrara G, Digilio MC, Cavaliere ML, van Hagen JM, Zampino G, van der Burgt I, Ferrero GB, Mazzanti L, Screpanti I, Yntema HG, Nillesen WM, Savarirayan R, Zenker M, Dallapiccola B, Gelb BD, Tartaglia M: Heterozygous germline mutations in the $C B L$ tumor supressor gene cause a Noonan syndrome-like phenotype. Am J Hum Genet 2010, 87:250-257.

20. Digilio MC, Conti E, Sarkozy A, Mingarelli R, Dottorini T, Marino B, Pizzuti A, Dallapiccola B: Grouping of multiple-lentigines/LEOPARD and Noonan sindrome on the PTPN11 gene. Am J Hum Genet 2002, 71:389-394.

21. Legius E, Schrander-Stumpel C, Schollen E, Pulles-Heintzberger C, Gewillig M, Fryns JP: PTPN11 mutations in LEOPARD syndrome. J Med Genet 2002. 39:571-574

22. Cordeddu V, Di Schiavi E, Pennacchio LA, Ma'ayan A, Sarkozy A, Fodale V, Cecchetti S, Cardinale A, Martin J, Schackwitz W, Lipzen A, Zampino G, Mazzanti L, Digilio MC, Martinelli S, Flex E, Lepri F, Bartholdi D, Kutsche K, Ferrero GB, Anichini C, Selicorni A, Rossi C, Tenconi R, Zenker M, Merlo D, Dallapiccola B, lyengar R, Bazzicalupo P, Gelb BD, Tartaglia M: Mutation of SHOC2 promotes aberrant protein N-myristoylation and causes Noonanlike syndrome with loose anagen hair. Nat Genet 2009, 41(9):1022-1026.

23. Niihori $T$, Aoki $Y$, Narumi $Y$, Neri G, Cavé $H$, Verloes A, Okamoto $N$, Hennekam RC, Gillessen-Kaesbach G, Wieczorek D, Kavamura MI, Kurosawa K, Ohashi H, Wilson L, Heron D, Bonneau D, Corona G, Kaname T, Naritomi K, Baumann C, Matsumoto N, Kato K, Kure S, Matsubara Y: Germline KRAS and BRAF mutations in cardio-facio-cutaneous syndrome. Nat Genet 2006, 38(3):294-296.

24. Rodriguez-Viciana P, Tetsu O, Tidyman WE, Estep AL, Conger BA, Cruz MS, McCormick F, Rauen KA: Germline mutations in genes within the MAPK pathway cause cardio-facio-cutaneous syndrome. Science 2006, 311(5765):1287-1290.

25. Aoki Y, Niihori T, Kawame H, Kurosawa K, Ohashi H, Tanaka Y, Filocamo M, Kato K, Suzuki Y, Kure S, Matsubara Y: Germline mutations in HRAS protooncogene cause Costello syndrome. Nat Genet 2005, 37(10):1038-1040.

26. Allanson JE, Bohring A, Dörr HG, Dufke A, Gillessen-Kaesbach G, Horn D, König R, Kratz CP, Kutsche K, Pauli S, Raskin S, Rauch A, Turner A, Wieczorek $D$, Zenker M: The face of Noonan syndrome: Does phenotype predict genotype. Am J Med Genet A 2010, 152A(8):1960-1966.

27. Helga T, James T, Robinson JT, Mesirov JP: Integrative Genomics Viewer (IGV): high-performance genomics data visualization and exploration. Brief Bioinform 2013, 14(2):178-92.

28. Robinson JT, Thorvaldsdóttir H, Winckler W, Guttman M, Lander ES, Getz G, Mesirov JP: Integrative Genomics Viewer. Nat Biotechnol 2011, 29:24-26.

29. Rehm HL, Bale SJ, Bayrak-Toydemir P, Berg JS, Brown KK, Deignan JL, Friez MJ, Funke BH, Hegde MR, Lyon E, Working Group of the American College of Medical Genetics and Genomics Laboratory Quality Assurance Commitee: ACMG clinical laboratory standards for next-generation sequencing. Genet Med. 2013, 15(9):733-747.
30. Lee BH, Kim JM, Jin HY, Kim GH, Choi JH, Yoo HW: Spectrum of mutations in Noonan syndrome and their correlation with phenotypes. J Pediatr 2011, 159(6):1029-1035.

31. Tartaglia M, Martinelli S, Stella L, Bocchinfuso G, Flex E, Cordeddu V, Zampino G, Burgt I, Palleschi A, Petrucci TC, Sorcini M, Schoch C, Foa R, Emanuel PD, Gelb BD: Diversity and functional consequences of germline and somatic PTPN11 mutations in human disease. Am J Hum Genet 2006, 78(2):279-290.

32. Zenker M, Voss E, Reis A: Mild variable Noonan syndrome in a family with a novel PTPN11 mutation. Eur J Med Genet 2007, 50(1):43-47.

33. Sarkozy A, Conti E, Digilio MC, Marino B, Morini E, Pacileo G, Wilson M, Calabrò R, Pizzuti A, Dallapiccola B: Clinical and molecular analysis of 30 patients with multiple lentigines LEOPARD syndrome. J Med Genet 2004, 41(5):e68.

34. Lepri F, De Luca A, Stella L, Rossi C, Baldassarre G, Pantaleoni F, Cordeddu V, Williams BJ, Dentici ML, Caputo V, Venanzi S, Bonaguro M, Kavamura I, Faienza MF, Pilotta A, Stanzial F, Faravelli F, Gabrielli O, Marino B, Neri G, Silengo MC, Ferrero GB, Torrrente I, Selicorni A, Mazzanti L, Digilio MC, Zampino G, Dallapiccola B, Gelb BD, Tartaglia M: SOS1 mutations in Noonan syndrome: molecular spectrum, structural insights on pathogenic effects, and genotype-phenotype correlations. Hum Mutat 2011, 32(7):760-772.

35. Dentici ML, Sarkozy A, Pantaleoni F, Carta C, Lepri F, Ferese R, Cordeddu V, Martinelli S, Briuglia S, Digilio MC, Zampino G, Tartaglia M, Dallapiccola B: Spectrum of MEK1 and MEK2 gene mutations in cardio-facio-cutaneous syndrome and genotype-phenotype correlations. Eur J Hum Genet 2009, 17(6):733-740.

36. Zenker M: Noonan syndrome and related disorders: A matter of deregulated Ras signaling. Monogr Hum Genet 2010, Vol. 17.

37. Tartaglia M, Gelb BD, Zenker M: Noonan syndrome and clinically related disorders. Best Pract Res Clin Endocrinol Metab 2011, 25(1):161-179.

38. Digilio MC, Lepri F, Baban A, Dentici ML, Versacci P, Capolino R, Ferese R, De Luca A, Tartaglia M, Marino B, Dallapiccola B: RASopathies: Clinical Diagnosis in the First Year of Life. Mol Syndromol 2011, 1(6):282-289.

39. Van der Burgt I: Noonan syndrome. Orphanet J Rare Dis 2007, 2:4.

40. Voron DA, Hatfield HH, Kalkhoff RK: Multiple lentigines syndrome. Case report and review of the literature. Am J Med 1976, 60:447-456.

41. Kavamura NI, Peres CA, Alchhorne MMA, Brunoni D: CFC index for the diagnosis of cardiofaciocutaneous syndrome. Am J Med Genet 2002, 112:12-16.

42. Aoki Y, Niihori T, Banjo T, Okamoto N, Mizuno S, Kurosawa K, Ogata T, Takada F, Yano M, Ando T, Hoshika T, Barnett C, Ohashi H, Kawame H, Hasegawa T, Okutani T, Nagashima T, Hasegawa S, Funayama R, Nagashima T, Nakayama K, Inoue S, Watanabe Y, Ogura T, Matsubara Y: Gain-of-Function Mutations in RIT1 Cause Noonan Syndrome, a RAS/ MAPK Pathway Syndrome. Am J Hum Genet 2013, 11:93.

doi:10.1186/1471-2350-15-14

Cite this article as: Lepri et al:: Diagnosis of Noonan syndrome and related disorders using target next generation sequencing. BMC Medical Genetics 2014 15:14

\section{Submit your next manuscript to BioMed Central and take full advantage of:}

- Convenient online submission

- Thorough peer review

- No space constraints or color figure charges

- Immediate publication on acceptance

- Inclusion in PubMed, CAS, Scopus and Google Scholar

- Research which is freely available for redistribution 